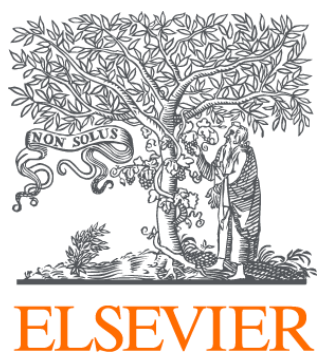

Since January 2020 Elsevier has created a COVID-19 resource centre with free information in English and Mandarin on the novel coronavirus COVID-

19. The COVID-19 resource centre is hosted on Elsevier Connect, the company's public news and information website.

Elsevier hereby grants permission to make all its COVID-19-related research that is available on the COVID-19 resource centre - including this research content - immediately available in PubMed Central and other publicly funded repositories, such as the WHO COVID database with rights for unrestricted research re-use and analyses in any form or by any means with acknowledgement of the original source. These permissions are granted for free by Elsevier for as long as the COVID-19 resource centre remains active. 


\section{Dossier scientifique}

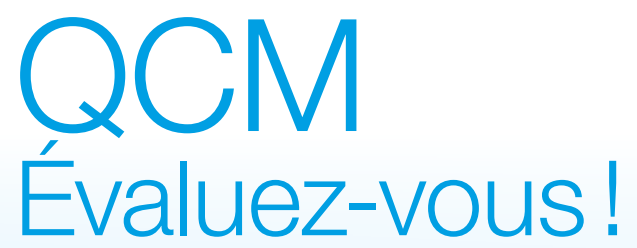

1 L'agent de la rougeole est un virus issu:

$\square$ A. Du virus de la peste bovine.

$\square$ B. Du virus de la rage.

$\square$ C. Du virus du SRAS.

$\square$ D. Du virus de la grippe.

2 Le réservoir du coronavirus du SRAS est plutôt à rechercher:
$\square$ A. Chez les oiseaux.
$\square$ B. Chez les carnivores.
$\square$ C. Chez les dromadaires.
$\square$ D. Chez les chiroptères.

\section{Le virus RABV:}

$\square$ A. Est excrété au plus tôt 3 jours avant la phase clinique chez le chien.

$\square$ B. Est excrété jusqu'à 29 jours avant la phase clinique chez le renard.

$\square$ C. Induit une incubation habituellement longue.

$\square$ D. Est surtout transmis à l'homme par les carnivores sauvages et les chauves-souris de l'Ancien Monde.

$\square$ E. Est le seul Lyssavirus zoonotique.

$\square$ F. Occasionne classiquement une hydrophobie chez le chien.

\section{Le diagnostic de la rage:}

$\square$ A. Fait surtout appel à la culture cellulaire.

$\square$ B. Peut être réalisé par tous les laboratoires vétérinaires départementaux pour la rage animale.

$\square$ C. Ne peut être réalisé qu'à l'Institut Pasteur de Paris en cas de suspicion de rage chez un animal si un humain a été en contact avec ce dernier durant la période possible d'excrétion.

$\square$ D. Est habituellement réalisé du vivant de l'animal.
5 Du virus de l'hépatite E vivant peut être présent dans:

$\square$ A. Les produits contenant du foie de veau cuit, consommés cuits.

$\square$ B. Les produits contenant du foie de porc cru, consommés cuits à cœur.

$\square$ C. Les produits contenant du foie de porc cru, consommés crus.

6 Quelle(s) profession(s) présente(nt) un risque accru d'exposition au virus de l'hépatite $E$ ?

$\square$ A. Les éleveurs de porcs.

$\square$ B. Les restaurateurs.

$\square$ C. Le personnel hospitalier.

$\square$ D. Les céréaliers.

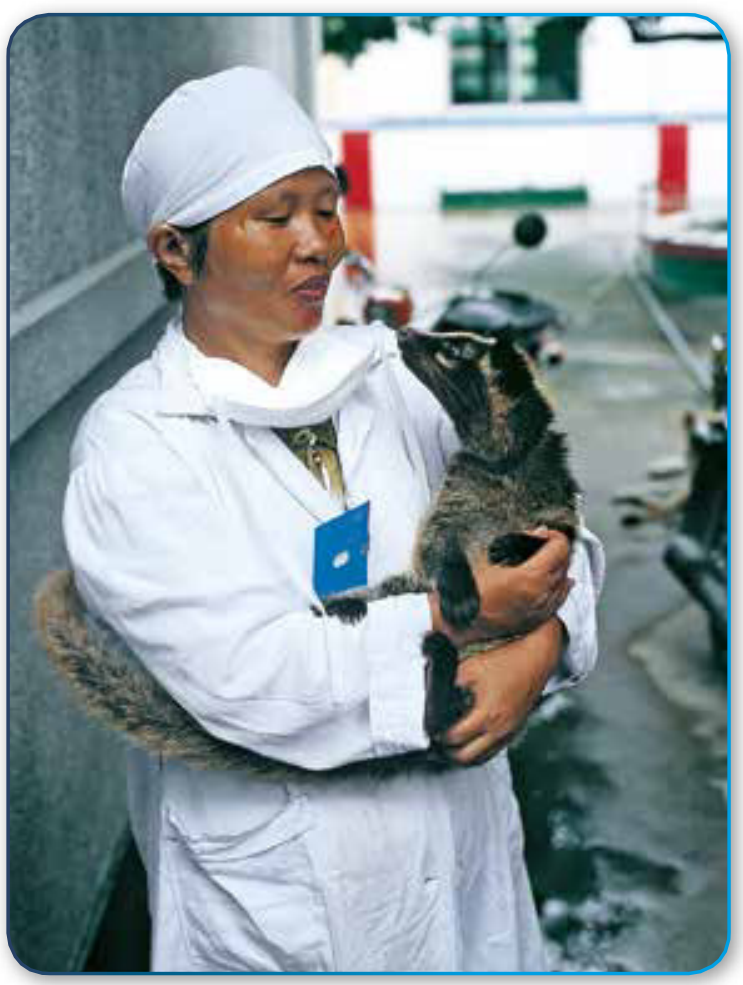


7 Comment la transmission de Chlamydia psittaci

à lhomme se produit-elle le plus souvent?

$\square$ A. Par inhalation d'aérosols contaminés.

$\square$ B. Lors de la manipulation d'oiseaux ou de tissus infectés.

$\square$ C. Par ingestion.

Quelles sont les espèces de Chlamydla

dont les principaux hôtes sont des oiseaux?
$\square$ A. Chlamydia abortus.
$\square$ B. Chlamydia psittaci.
$\square$ C. Chlamydia pecorum.
$\square$ D. Chlamydia gallinacea.
$\square$ E. Chlamydia avium.

\section{La réapparition de Mycobacterium bovis}

dans les élevages bovins français:

$\square$ A. Concerne surtout aujourd'hui les élevages producteurs de lait.

$\square$ B. Est surtout importante en Bretagne.

$\square$ C. Est en partie liée à l'augmentation de la taille des élevages, ce qui augmente les risques de contamination et limite les risques de détection précoce.

$\square$ D. Conduit à un risque considéré aujourd'hui comme élevé pour la santé publique (SP).

\section{Linfection à Mycobacterium bovis \\ dans la faune sauvage en France:}

$\square$ A. Concerne exclusivement les sangliers et les blaireaux.

$\square$ B. Est très ancienne et a été mise en évidence sur des sangliers dans les années 1980.

$\square$ C. A toujours été trouvée jusqu'à aujourd'hui, exclusivement à proximité de foyers bovins.

$\square$ D. Peut actuellement être contrôlée par une vaccination des blaireaux et des sangliers à l'aide du BCG administré par voie orale.

\section{La principale espèce de tique impliquée} dans la vectorisation de Rickettisa conort est.

$\square$ A. Ixodes ricinus.

$\square$ B. Dermacentor reticulatus.

$\square$ C. Rhipicephalus sanguineus.

Le diagnostic biologique de borréliose de Lyme chez les animaux s'appuie principalement sur:

$\square$ A. Sérologie par immunofluorescence.

$\square$ B. Sérologie par ELISA.

$\square$ C. Sérologie par Western Blot.

$\square$ D. Culture.

$\square$ E. PCR sur biopsie.

$\square$ F. PCR sur sang.

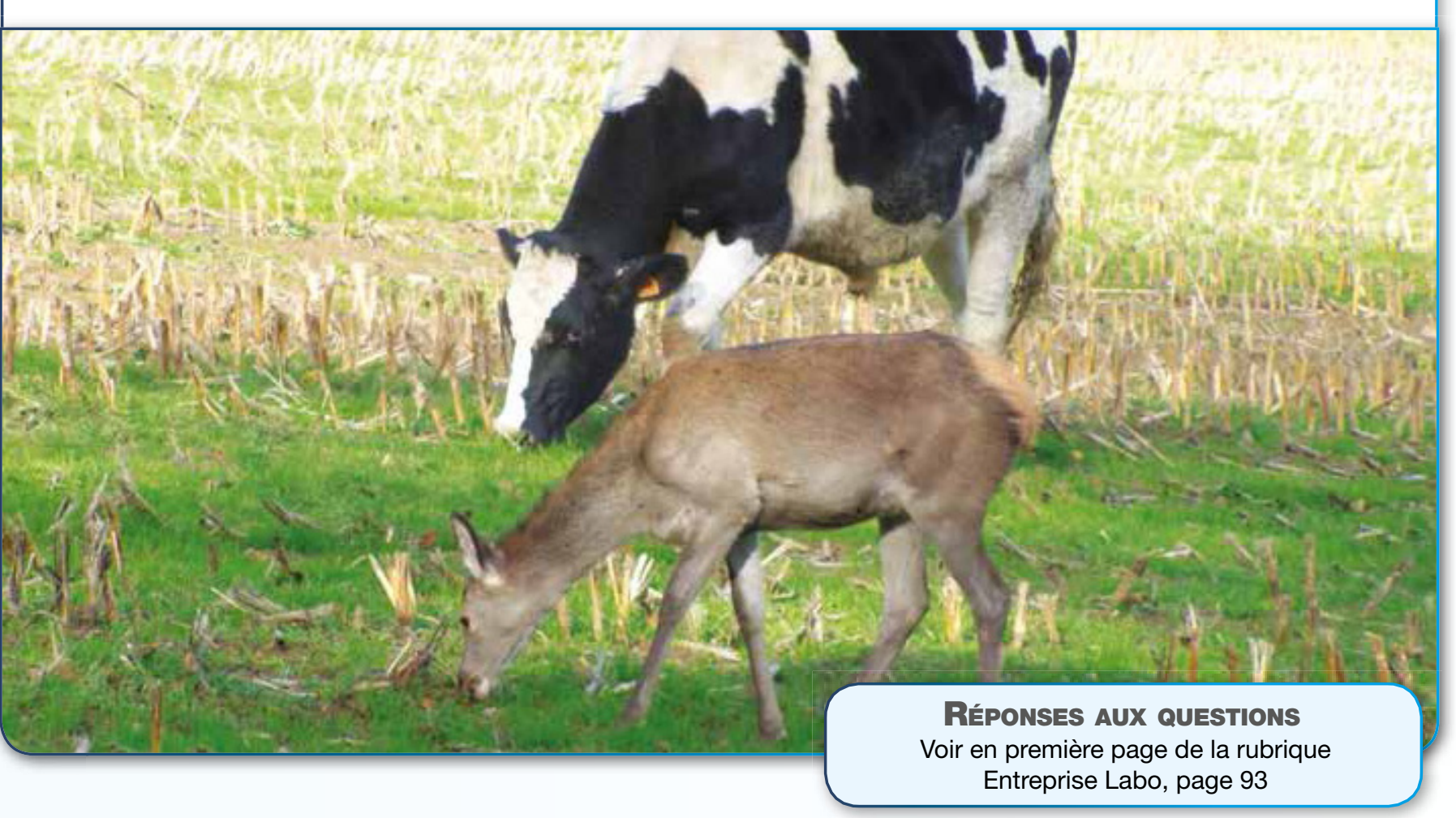

